\title{
Annurca Apple Nutraceutical Formulation Enhances Keratin Expression in a Human Model of Skin and Promotes Hair Growth and Tropism in a Randomized Clinical Trial
}

\author{
Gian Carlo Tenore, Domenico Caruso, Giuseppe Buonomo, Maria D'Avino, \\ Rita Santamaria, ${ }^{1}$ Carlo Irace, ${ }^{1}$ Marialuisa Piccolo, ${ }^{1}$ Maria Maisto, ${ }^{1}$ and Ettore Novellino ${ }^{1}$ \\ ${ }^{1}$ Department of Pharmacy, University of Naples Federico II, Naples, Italy. \\ ${ }^{2}$ Department of Internal Medicine, Hospital Cardarelli, Naples, Italy. \\ ${ }^{3}$ Coop. Samnium Medica, Benevento, Italy.
}

\begin{abstract}
Several pharmaceutical products have been formulated over the past decades for the treatment of male and female alopecia, and pattern baldness, but relatively few metadata on their efficacy have been published. For these reasons, the pharmaceutical and medical attention has recently focused on the discovery of new and safer remedies. Particularly, great interest has been attracted by oligomeric procyanidin bioactivity, able to promote hair epithelial cell growth as well as to induce the anagen phase. Specifically, the procyanidin B2, a dimeric derivative extracted from apples, has demonstrated to be one of the most effective and safest natural compounds in promoting hair growth, both in vitro and in humans by topical applications. By evaluating the polyphenolic content of different apple varieties, we have recently found in the apple fruits of cv Annurca (AFA), native to Southern Italy, one of the highest contents of oligomeric procyanidins, and, specifically, of procyanidin B2. Thus, in the present work we explored the in vitro bioactivity of AFA polyphenolic extract as a nutraceutical formulation, named AppleMets (AMS), highlighting its effects on the cellular keratin expression in a human experimental model of adult skin. Successively, testing the effects of AMS on hair growth and tropism in healthy subjects, we observed significant results in terms of increased hair growth, density, and keratin content, already after 2 months. This study proves for the first time the impact of apple procyanidin B2 on keratin biosynthesis in vitro, and highlights its effect as a nutraceutical on human hair growth and tropism.
\end{abstract}

\section{KEYWORDS: • Annurca apple • hair growth • keratin expression $\bullet$ keratinocytes $\bullet$ nutraceutical $\bullet$ polyphenols - randomized clinical trial}

\section{INTRODUCTION}

$\mathbf{S}$ EVERAl PHaRMaceutical PRoducts have been formulated over the past decades for the treatment of male and female alopecia and pattern baldness. ${ }^{1}$ These most common forms of hair loss in men and women, affecting $\sim 50 \%$ of the adult population, are nonstop processes that flow toward a definite pattern of alopecia in genetically predisposed individuals. Although clinically different, the pathogenic pathways leading to this type of hair loss are thought to be similar in both sexes. ${ }^{2}$ Minoxidil, which was originally synthesized as a potassium channel opener ${ }^{3}$ and initially prescribed for hypertension, is an FDA-approved topical medication for curing male pattern baldness. ${ }^{4,5}$ Recently, finasteride, which

Manuscript received 30 January 2017. Revision accepted 10 July 2017.

Address correspondence to: Ettore Novellino, PhD, Department of Pharmacy, University of Naples Federico II, Via D. Montesano 49, Naples 80131, Italy, E-mail: ettore.novellino@ unina.it

(C) Gian Carlo Tenore et al., 2018; Published by Mary Ann Liebert, Inc. This is an Open Access article distributed under the terms of the Creative Commons Attribution License, which permits unrestricted use, distribution, and reproduction in any medium, provided the original work is properly cited. is a type II $5 \alpha$-reductase inhibitor and was initially used for curing prostatic hypertrophy, ${ }^{6,7}$ has been approved by the FDA as an oral drug for male hair loss therapy. ${ }^{8}$ Nevertheless, side effects have been reported for both agents, ${ }^{9-12}$ thereby considerably limiting their clinical use.

In this perspective, the pharmaceutical and medical attention has recently focused on the discovery of new and safer remedies. Particularly, in search of biological products that possess hair growing activity, great interest has been attracted by oligomeric procyanidins, extracted from grape seeds, able to promote hair epithelial cell growth as well as to induce anagen phase, at almost the same intensity of minoxidil. ${ }^{13}$ Specifically, procyanidin B2 has demonstrated to be one of the most effective and safest natural compounds in promoting hair growth, both in vitro ${ }^{14}$ and in humans by topical applications. ${ }^{15,16}$ During hair growth and keratinization process along the hair fiber, several keratins arrange into filaments to contribute to the production of the hair shaft. ${ }^{17}$ These multigene proteins are members of the intermediate filament (IF) family, including "soft keratins" expressed preferentially in epithelial tissues and "hard 
keratins" involved in the formation of hard keratinized structures such as hairs and nails. ${ }^{18}$ Epithelial cells express cytokeratins assembled in IFs by the polymerization of heterodimers consisting of one type I (acidic) and one type II (basic to neutral) protein. ${ }^{19}$ Currently, more than 50 different IF proteins have been identified and classified into six groups based on their amino acid sequence. ${ }^{20}$

By evaluating the polyphenolic content of different apple varieties, we have recently found in the apple fruits of $\mathrm{cv}$ Annurca (AFA), native of Southern Italy, one of the highest contents of oligomeric procyanidins, and, specifically, of procyanidin B2, with respect to more common apple samples, such as Red Delicious, Granny Smith, Pink Lady, Fuji, and Golden Delicious. ${ }^{21}$ Encouraged by these results, the first aim of the present work was to explore the bioactivity of AFA polyphenolic extract, highlighting the effects of its supplementation on cellular keratin expression by targeted bioscreen in vitro. For this reason, we focused on a wellcharacterized human experimental model of adult skin based on normal human keratinocyte (HaCaT cells). ${ }^{22}$ This cell line retains a capacity for differentiation similar to normal human epidermal keratinocytes and hence offers a suitable model for the study of keratinization as well as of epidermal homeostasis. ${ }^{23}$ Then, the second goal was to evaluate the effects of AFA extract supplementation as a nutraceutical, on hair growth and tropism in healthy subjects. In this regard, according to our previous knowledge about the effects of salivary and gastric digestion on the bioaccessibility of active components, we used a specific formulation consisting of gastro-protected capsules. ${ }^{24}$

The present study shows, for the first time, the impact of procyanidin $\mathrm{B} 2$, contained in apple natural extract, on keratin biosynthesis in vitro, and represents the first attempt of its oral administration to humans as a potential hair growing nutraceutical agent.

\section{MATERIALS AND METHODS}

\section{Apple collection}

Annurca (M. pumila Miller cv Annurca) apple fruits (each, about $100 \mathrm{~g}$ ) were collected in Valle di Maddaloni (Caserta, Italy) in October when fruits had just been harvested (green peel). The fruits were reddened, following the typical treatment for about 30 days, ${ }^{25}$ and then analyzed.

\section{Preparation of AFA supplements (AMS and AMSbzs)}

AFA (whole fruits, peel, and pulp) have been repeatedly extracted with water, the obtained solution has been filtered, centrifuged, and concentrated. Then, the solution has been spray-dried in combination with maltodextrins, obtaining a fine powder named AppleMetS (AMS). With regard to the clinical trial, the AFA supplements used in this study consisted of two different types of gastric-resistant capsules containing (1) AFA polyphenolic extract microencapsulated with maltodextrins (400 mg) (AMS) and (2) AFA polyphenolic extract microencapsulated with maltodextrins $(400 \mathrm{mg})$, biotin $(0.20 \mathrm{mg})$, selenomethionine $(80.0 \mu \mathrm{g})$, and zinc ace- tate $(21.0 \mathrm{mg})$, named AppleMetS Hair (AMSbzs). The choice of using gastric-resistant capsules was due to our previous knowledge about the effects of salivary and gastric digestion on the bioaccessibility of bioactive components. ${ }^{24}$ Both supplements were formulated by the Department of Pharmacy, University of Naples "Federico II" (Naples, Italy). Large-scale production of both supplements was accomplished by MB-Med Company (Turin, Italy).

\section{Cell cultures and treatments}

HaCaT cells, an immortalized, nontumorigenic human keratinocyte cell line, were cultured in Dulbecco's modified Eagle's medium (DMEM; Invitrogen, Paisley, United Kingdom) containing high glucose $(4.5 \mathrm{~g} / \mathrm{L})$, supplemented with $10 \%$ fetal bovine serum (FBS; Cambrex, Verviers, Belgium), L-glutamine (2 mM; Sigma, Milan, Italy), penicillin $(100 \mathrm{U} / \mathrm{mL}$; Sigma), and streptomycin $(100 \mu \mathrm{g} / \mathrm{mL}$; Sigma) at $37^{\circ} \mathrm{C}$ in a humidified $5 \% \mathrm{CO}_{2}$ atmosphere.

For in vitro experiments, subconfluent cultures of $\mathrm{HaCaT}$ cells were incubated in the presence or absence of FBS with a range of AMS concentrations from 0.009 to $2.3 \mathrm{mg} / \mathrm{mL}$ for established times.

\section{In vitro bioscreens}

Before evaluating the biological effects of AFA polyphenolic extract (AMS) on the regulation of keratin expression, preliminary experiments were allowed to finalize the experimental model and to define specific protocols for suitable in vitro treatments. Biochemical and toxicological investigations were thereby performed to explore AMS bioactivity in human keratinocytes ( $\mathrm{HaCaT}$ cell line) in vitro, focusing on the evaluation of cell viability as well as on cell growth and proliferation following exposure up to $48 \mathrm{~h}$ to various AMS concentrations. As follows, optimal experimental conditions of cell growth and protein biosynthesis, relative to both extract concentration and incubation times, were set up by means of targeted bioscreens. In detail, the experimental procedure involved the estimation of a "cell survival index," arising from the combination of cell viability evaluation with cell counting. ${ }^{26} \mathrm{HaCaT}$ cells were inoculated in 96-microwell culture plates at a density of $10^{4}$ cells/well and allowed to grow for $24 \mathrm{~h}$. The medium was then replaced with fresh medium and cells were treated for further $48 \mathrm{~h}$ with a range of concentrations $(0.009,0.09$, $0.23,0.46,0.92,1.68$, and $2.3 \mathrm{mg} / \mathrm{mL}$ ) of extract.

Using the same experimental procedure, cell cultures were also incubated with cisplatin (cis-diamminedichloroplatinum [cDDP]), as a positive control for cytotoxic effects. Cell viability was evaluated using the MTT assay procedure, which measures the level of mitochondrial dehydrogenase activity using the yellow 3-(4,5-dimethyl-2-thiazolyl)-2,5-diphenyl2H-tetrazolium bromide (MTT; Sigma) as substrate. The assay is based on the redox ability of living mitochondria to convert dissolved MTT into insoluble purple formazan. Briefly, after the treatments, the medium was removed and the cells were incubated with $20 \mu \mathrm{L} /$ well of MTT solution $(5 \mathrm{mg} / \mathrm{mL})$ for $1 \mathrm{~h}$ in a humidified $5 \% \mathrm{CO}_{2}$ incubator at $37^{\circ} \mathrm{C}$. 
The incubation was stopped by removing the MTT solution and by adding $100 \mu \mathrm{L} /$ well of DMSO to solubilize the obtained formazan. Finally, the absorbance was monitored at $550 \mathrm{~nm}$ using a microplate reader (iMark microplate reader; Bio-Rad). Cell number was determined by the TC10 automated cell counter (Bio-Rad), providing an accurate and reproducible total count of cells and a live/dead ratio in one step by a specific dye (trypan blue) exclusion assay. Bio-Rad's TC10 automated cell counter uses disposable slides, TC10 trypan blue dye $(0.49 \mathrm{~g} / 100 \mathrm{~mL}$ trypan blue dye in $0.81 \mathrm{~g} / 100$ $\mathrm{mL}$ sodium chloride and $0.06 \mathrm{~g} / 100 \mathrm{~mL}$ potassium phosphate dibasic solution), and a CCD camera to count cells based on the analyses of captured images. Once the loaded slide is inserted into the slide port, the TC10 automatically focuses on the cells, detects the presence of trypan blue dye, and provides the count. When cells are damaged or dead, trypan blue can enter the cell allowing living cells to be counted. Operationally, after treatments in 96-microwell culture plates, the medium was removed and the cells were collected. Ten microliters of cell suspension, mixed with $0.4 \mathrm{~g} / 100 \mathrm{~mL}$ trypan blue solution at 1:1 ratio, was loaded into the chambers of disposable slides. The results are displayed as total cell count (number of cells per milliliter). If trypan blue is detected, the instrument also accounts for the dilution and shows live cell count and percent viability. Total counts and live/dead ratio from random samples for each cell line were subjected to comparisons with manual hemocytometers in control experiments. The calculation of the concentration required to inhibit the net increase in the cell number and viability by $50 \%$ $\left(\mathrm{IC}_{50}\right)$ is based on plots of data ( $n=6$ for each experiment) and repeated five times (total $n=30$ ). $\mathrm{IC}_{50}$ values were obtained by means of a dose/response curve by nonlinear regression using a curve fitting program, GraphPad Prism 5.0, and are expressed as mean value \pm standard error of the mean (SEM) $(n=30)$ of five independent experiments.

The evaluation of the relative number of live and dead cells was performed by a MultiTox-Fluor Multiplex Cytotoxicity Assay (Promega, Madison, WI). Briefly, cells were plated into 96-well plates $\left(5 \times 10^{3} /\right.$ well $)$ and, after the treatments with AMS as before described, the solution containing the fluorogenic substrates for the measurements of live-cell and deadcell protease activities was added to the cells. Following $30 \mathrm{~min}$ at $37^{\circ} \mathrm{C}$, the fluorescence was determined in a Perkin Elmer microplate reader (Perkin Elmer LS 55 Luminescence Spectrometer, Beaconsfield, United Kingdom) using a filter combination with an excitation wavelength of $400 / 485 \mathrm{~nm}$ and an emission wavelength of 505/520 nm (slits $5 \mathrm{~nm}$ ). Data are expressed as percentage of viable cell versus control cultures.

\section{Cell morphology analysis}

The human keratinocyte cell line was grown on $60-\mathrm{mm}$ culture dishes by plating $5 \times 10^{5}$ cells. After reaching subconfluence, cells were incubated for 24 and $48 \mathrm{~h}$ with a range of concentrations of AMS $(0.09,0.23,0.46,0.92$, and $2.3 \mathrm{mg} / \mathrm{mL}$ ) under the same in vitro experimental conditions described above, and were then morphologically examined by a phase-contrast microscope (Labovert microscope;
Leitz). Microphotographs at a $200 \times$ total magnification $(20 \times$ objective and $10 \times$ eyepiece) were taken with a standard VCR camera (Nikon).

\section{Preparation of cellular extracts}

$\mathrm{HaCaT}$ cells were grown for $48 \mathrm{~h}$ in the presence or absence of AMS at different concentrations $(0.23$ and $0.46 \mathrm{mg} / \mathrm{mL})$, as established after preliminary bioscreens. Following treatments, protein extracts were prepared according to the previously described procedure..$^{27}$ Briefly, cell pellets were lysed at $4^{\circ} \mathrm{C}$ for 10 min with a buffer containing $1 \mathrm{~g} / 100 \mathrm{~mL}$ Triton X-100, $5 \mathrm{mM}$ EDTA, in PBS (pH 7.4) containing protease inhibitors. After centrifugation at $14,000 \mathrm{~g}$ for $10 \mathrm{~min}$ at $4^{\circ} \mathrm{C}$, the supernatant was collected as the soluble fraction and stored at $-80^{\circ} \mathrm{C}$. The pellet was homogenized at $4^{\circ} \mathrm{C}$ for $30 \mathrm{~min}$ in $1 \mathrm{~mL}$ of $10 \mathrm{mM}$ Tris- $\mathrm{HCl}, \mathrm{pH} 7.6,140 \mathrm{mM} \mathrm{NaCl}, 1.5 \mathrm{M} \mathrm{KCl}, 5 \mathrm{mM}$ EDTA, $0.5 \%$ Triton X-100, and protease inhibitors. The supernatant fraction was obtained by centrifugation at $15,000 \mathrm{~g}$ for $10 \mathrm{~min}$ at $4^{\circ} \mathrm{C}$ and then stored at $-80^{\circ} \mathrm{C} .{ }^{22}$ Protein concentration was determined by the Bio-Rad protein assay (Bio-Rad).

\section{Western blot analysis}

Defined amounts $(70 \mu \mathrm{g})$ of proteins from soluble cellular extracts were loaded and separated on 10\% SDS-PAGE and electrotransferred onto a nitrocellulose membrane (GE Healthcare Life Sciences, United Kingdom) using a BioRad Transblot (Bio-Rad). Proteins were visualized by reversible staining with Ponceau-S solution and destained in PBS. Membranes were blocked at room temperature in milk buffer $(1 \times$ PBS, $5-10 \mathrm{~g} / 100 \mathrm{~mL}$ non fat dry milk, $0.2 \% \mathrm{~g} /$ $100 \mathrm{~mL}$ Tween-20) and then incubated at $4{ }^{\circ} \mathrm{C}$ overnight with 1:250 monoclonal anti-pan cytokeratin antibodies (mixture) (Sigma-Aldrich, Milan, Italy), which recognize the following human cytokeratins, according to their molecular weight: K1 (68 kDa), K4 (59 kDa), K5 (58 kDa), K6/ K10 (56 kDa), K13 (54 kDa), K8 (52 kDa), K18 (45 kDa), and $\mathrm{K} 19(40 \mathrm{kDa})$. As a secondary antibody, a goat antimouse IgG+IgM (1:5000; Jackson ImmunoResearch Laboratories, Baltimore Pike, West Grove, PA, USA) was used. The immunocomplexes were visualized by the ECL chemiluminescence method (ECL, Amersham Biosciences, United Kingdom) and analyzed by an imaging system (ImageQuant ${ }^{\mathrm{TM}}$ 400; GE Healthcare Life Sciences). Densitometric analyses were conducted using the GS-800 imaging densitometer (Bio-Rad). The GAPDH antibody (SigmaAldrich) was used to normalize the results.

\section{Study population and protocol}

Study participants were recruited by the Samnium Medical Cooperative (Benevento, Italy). Patients were enrolled in November 2015. Patients aged 30-83 years were eligible for enrollment if they showed evidence of pattern baldness. The subjects were asked to keep their dietary habits unchanged throughout the entire study.

Exclusion criteria were as follows: smoking, obesity (body mass index $[\mathrm{BMI}]>30 \mathrm{~kg} / \mathrm{m}^{2}$ ), diabetes, hepatic disease, renal 
disease, heart disease, family history of chronic diseases, drug therapy or supplement intake for hair growth, drug therapy or supplement intake containing apple polyphenols, heavy physical exercise ( $>10 \mathrm{~h} /$ week), pregnant women, women suspected of being pregnant, women who hoped to become pregnant, breastfeeding, birch pollen allergy, use of vitamin/ mineral supplements 2 weeks before entry into the study, and donation of blood less than 3 months before the study.

The subjects received oral and written information concerning the study before they gave their written consent. Protocol, letter of intent of volunteers, and synoptic document about the study were submitted to the Scientific Ethics Committee of AO Rummo Hospital (Benevento, Italy). The study was approved by the committee and carried out in accordance with the Helsinki Declaration of 1964 (as revised in 2000). The subjects were asked to make records in an intake-checking table for the intervention study and side effects in daily reports. The study was a monocentric, randomized, double-blind, placebo-controlled trial conducted at the Samnium Medical Cooperative (Benevento, Italy).

The study duration was 16 weeks: the group underwent 4 weeks of placebo treatment, consisting in the administration of identically appearing capsules containing only maltodextrin, followed by 8 weeks of nutraceutical treatment and 4 weeks of follow-up. Both the examinations and the study treatment were performed in an outpatient setting. Clinic visits and hair sampling were performed at weeks $0,4,8,12$, and 16. Hair counts were carried out per area $\left(\mathrm{cm}^{2}\right)$ of a predetermined site of bald head skin, by three independent investigators three times each in double-blind mode. A number of 100 hairs ( $1 \mathrm{~cm}$ long) were sampled in the neck. Hairs were weighed by using an ABJ 320-4NM analytical balance (Zetalab Ltd., Padova, Italy). The hair keratin content was evaluated by first defatting hair samples with $n$-hexane and petroleum ether (4:1) for $4 \mathrm{~h}$ in a Soxhlet apparatus, and then estimating the protein content according to the Kjeldahl method 920.87 , by using a PBI International model Mineral SIX digester (PBI International, Milan, Italy) and a Buchi model B-324 distillation unit (Buchi, Flawil, Switzerland). ${ }^{28}$

Clinic visits, and blood sampling to test hepatic and renal toxicity, were performed after $12 \mathrm{~h}$ of fasting at weeks $0,4,8$, 12 , and 16. Subjects were informed not to drink alcohol or perform hard physical activity $48 \mathrm{~h}$ before blood sampling. All blood samples were taken in the morning and immediately after measurement of heart rate and blood pressure. Blood samples were collected in 10-mL EDTA-coated tubes (Becton-Dickinson, Plymouth, United Kingdom) and plasma was isolated by centrifugation $\left(20 \mathrm{~min}, 2200 \mathrm{~g}, 4^{\circ} \mathrm{C}\right)$. All samples were stored at $-80^{\circ} \mathrm{C}$ until analysis. Plasma aspartate aminotransferase (AST), alanine transaminase (ALT), gamma-glutamyl transpeptidase ( $\gamma$-GTP), alkaline phosphatase (ALP), lactate dehydrogenase (LDH), albumin, total bilirubin, and creatinine levels were determined on a Diacron International Free Carpe Diem, using commercially available kits from Diacron International (Grosseto, Italy). In addition to these five meetings, five standardized telephone interviews were performed starting from the first meeting to verify compliance and increase protocol adherence. In particular, these interviews reminded patients to complete their intakechecking table for the intervention study and to record any discontinuation or adverse events they might have experienced in the meantime (which were also documented regularly on the case report forms during each telephone and clinic visit). All patients underwent a standardized physical examination, assessment of medical history (for up to 5 years before enrollment), laboratory examination, measurement of blood pressure and heart rate, and evaluation of BMI. At each clinic visit, patients had to complete three self-administered questionnaires on quality-of-life aspects, and their diaries were checked for data completeness and quality of documentation to ensure patient comprehension of the diary items.

\section{Randomization, concealment, and blinding}

A total of 250 eligible patients were randomly assigned to two groups to receive AMS or AMSbzs supplements. Supplements and placebo were coded with different colors and given in random order. The code was not broken until all analyses were completed and the results were analyzed statistically. If a patient dropped out before receiving supplement, he or she was replaced by the next eligible patient enrolled at the same center. The concealed allocation was performed by an Internet-based randomization schedule, stratified by study site. The random number list was generated by an investigator with no clinical involvement in the trial. Patients, clinicians, core laboratories, and trial staff (data analysts, statisticians) were blind to treatment allocation.

\section{Study treatments}

The group of 250 patients (116 men and 134 women, 3083 years of age) was randomly divided into two subgroups (each one of 125 subjects, 58 men and 67 women). The two subgroups were instructed to take two capsules of AMS or AMSbzs per day (one capsule in the morning and one capsule in the evening). Noteworthy, the daily dose of AFA polyphenolic extract, adopted for the clinical trial, was in full accordance with the maximum polyphenolic extract daily intake (1000 mg), through food supplements and novel foods, indicated by the revised form (January 2015) of the Commission Regulation (EC) No. 258/1997 as the safe polyphenolic daily amount compatible with a good health state. Moreover, the quantities of biotin, selenium, and zinc have been calculated on the basis established by the Italian Ministry of Health (DM Revision June 2016) with regard to the maximum levels of vitamins and minerals allowed in food supplements, in accordance with that reported by the current European regulation about the minimum daily requirement (nutrient reference values [NRVs]) of vitamins and minerals (Reg. UE 1169/2011).

\section{Study outcomes and data collection}

Primary and secondary efficacy outcomes. The primary endpoint measured was the increase in the hair number $/ \mathrm{cm}^{2}$ area of bald head skin ( $>5 \%$ after 30 days, $>10 \%$ after 60 days), while key secondary outcomes were the increase in the weight 
and keratin content of hair samples collected (in both cases: $>5 \%$ after 30 days, $>10 \%$ after 60 days). All raw patient ratings were evaluated in a blinded manner at the site of the principal investigator. The decision process was performed according to a consensus document (unpublished standard operating procedure) before unblinding to define conclusive primary and secondary efficacy data from a clinical perspective.

Safety. Although no specific toxicity studies have been performed herein, mutagenicity tests and acute/subacute toxicity studies have long since demonstrated the safety of polyphenol content of apples both in mice and human beings. Specifically, the Commission Regulation (EC) No. 258/1997 established $1000 \mathrm{mg}$ as maximum polyphenolic extract daily intake in humans. Accordingly, the AFA polyphenolic extract dose adopted for the trial was an amount reasonably lower than that regarded as safe in humans. Moreover, the daily quantities of biotin, selenium, and zinc administered to patients were in compliance with the guidelines from the Italian Ministry of Health (DM Revision June 2016) regarding the maximum levels of vi- tamins and minerals allowed in food supplements, in accordance with what has been established by the current European regulation about the minimum daily requirement (NRVs) of vitamins and minerals (Reg. UE 1169/2011). Nevertheless, we assessed safety from reports of adverse events as well as laboratory parameters concerning hepatic and renal function, vital signs (blood pressure, pulse, height, weight, and BMI), and physical or neurological examinations. Safety was assessed over the entire treatment period at weeks $0,4,8,12$, and 16 , including adverse events occurring in the first 3 weeks after cessation of treatments. During the test, all subjects underwent a clinical diagnosis by a dermatologist, focusing on any adverse dermatological reaction such as inflammation, erythema, or eczema.

\section{Statistics}

Methodology. All the in vitro experiments have been repeated four times. Data are presented as mean \pm SEM, and statistical analysis was performed using GraphPad Prism (GraphPad software, Inc., San Diego, CA), and ANOVA test for multiple comparisons followed by Bonferroni's test.
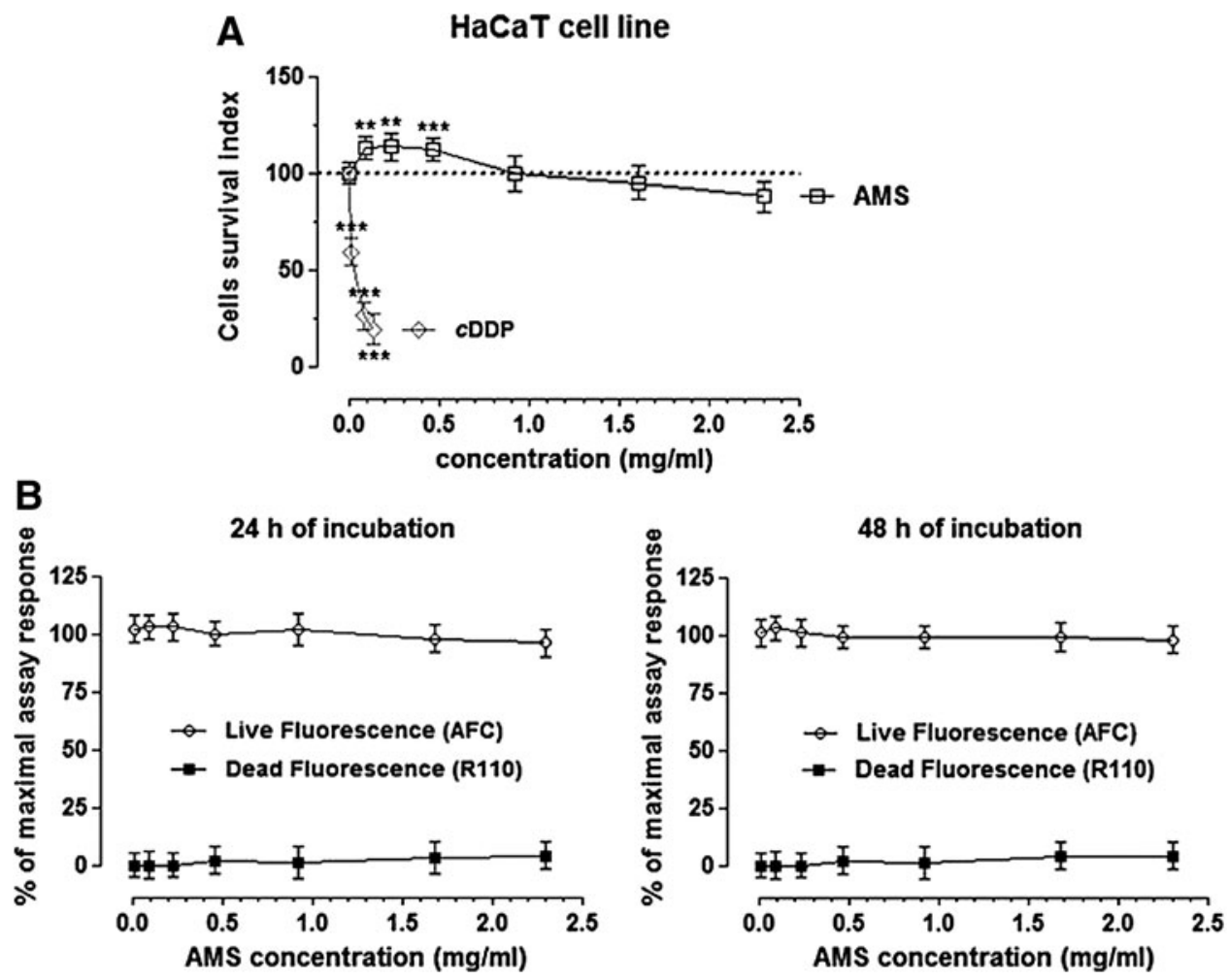

FIG. 1. AMS bioactivity in vitro. (A) Cell survival index, evaluated by the MTT assay and the determination of live/dead cell ratio. Human keratinocytes (HaCaT cells) were treated for $48 \mathrm{~h}$ with a range of concentrations (from 0.09 to $2.3 \mathrm{mg} / \mathrm{mL}$ ) of AMS (Annurca apple polyphenolic extract microencapsulated with maltodextrins, AppleMetS). Results are expressed in line graph as the percentage of cell survival index to untreated control cultures and are reported as mean $\pm \operatorname{SEM}(n=5)$ of three independent experiments. Cisplatin is the positive control for cytotoxicity $(c \mathrm{DDP})$. The amounts of cisplatin used to estimate its concentration/effect curve are reported as $\mathrm{mg} / \mathrm{mL}\left(3 \times 10^{-3}, 7.5 \times 10^{-3}, 1.5 \times 10^{-2}\right)$, corresponding to 10 , 25, and 50 micromolar concentrations, respectively. $* * * P<.001$ versus control (untreated cells); $* * P<.01$ versus control (untreated cells). (B) Inversely correlated fluorescent measures for live and dead cell counting after AMS treatments. HaCaT cells were incubated with AMS for the indicated times ( 24 and $48 \mathrm{~h}$ ) and concentrations (from 0.009 to $2.3 \mathrm{mg} / \mathrm{mL}$ ), and then the MultiTox-Fluor Multiplex Cytotoxicity Assay (Promega) was performed according to the manufacturer's instructions. Results are reported in line graphs as mean percentage \pm SEM $(n=5)$ of live and dead cells of four independent experiments. $c$ DDP, cis-diamminedichloroplatinum; SEM, standard error of the mean. 
During the trial, it became apparent that dropouts and incomplete diary documentation created missing data that could not be adequately handled by the intended robust comparison. To deal with the missing data structure, we used a negative, binomial, generalized, linear mixed-effects model (NB GLMM) that not only yields unbiased parameter estimates when missing observations are missing at random $(\mathrm{MAR})^{29}$ but also provides reasonably stable results even when the assumption of MAR is violated. ${ }^{30,31}$ Patients who did not provide any diary data (leading to zero evaluable days) were excluded from the MAR-based primary efficacy analysis, according to an "all observed data approach" as proposed by White et al..$^{32}$ This approach is statistically efficient without using multiple imputation techniques. ${ }^{33}$ Data retrieved after withdrawal of randomized study treatment were also included in the analysis. All of the trial experimental results are expressed as mean \pm standard deviation (SD) of four replications for each patient. Statistical analysis of data was performed by the Student's $t$ test or twoway ANOVA followed by the Tukey-Kramer multiple comparison test to evaluate significant differences between a pair of means. The statistic heterogeneity was assessed by using Cochran's test $(P<0.1)$. The $I^{2}$ statistic was also calculated, and $I^{2}>50 \%$ was considered as significant heterogeneity across studies. A random-effects model was used if significant heterogeneity was shown among the trials. Otherwise, results were obtained from a fixed-effects model. Percent change in mean and SD values was excluded when extracting SD values for an outcome. SD values were calculated from standard errors, 95\% CIs, $P$-values, or $t$ if they were not available directly. Previously defined subgroup analyses were performed to examine the possible sources of heterogeneity within these studies and included health status, study design, type of intervention, duration, total polyphenol dose, and Jadad score. Treatment effects were analyzed using PROC MIXED with treatment (placebo, apple supplements) and period as fixed factors, subject as random factor, and baseline measurements as covariates, and defined as weighted mean difference and 95\% CIs calculated for net changes in serum parameters and blood pressure values. Data that could not meet the criteria of variance homogeneity (Levene's test) and normal distribution (determined by residual plot examination and Shapiro-Wilk test) even after log transformation were analyzed by a nonparametric test (Friedman). The level of significance $(\alpha$-value) was $95 \%$ in all cases $(P<.05)$.

Analysis sets. The full analysis set population included all randomized patients and patients who did not fail to satisfy a major entry criterion. We excluded patients who provided neither primary nor secondary efficacy data from efficacy analyses. The per protocol set consisted of all patients who did not substantially deviate from the protocol; they had two characteristics. First, this group included patients for whom no major protocol violations were detected (e.g., poor compliance, errors in treatment assignment). Second, they had to have been on treatment for at least 50 days counting from day of first intake (completion of a certain prespecified minimal exposure to the treatment regimen). Hence, patients who prematurely discontinued the study or treatment before day 44 were excluded from the per protocol sample.

\section{Patient involvement}

No patients were involved in setting the research question or the outcome measures, nor were they involved in developing plans for participant recruitment or the design and implementation of the study. There are no plans to explicitly involve patients in dissemination. Final results will be sent to all participating sites.

\section{RESULTS}

\section{In vitro bioscreen}

The results are presented in Figure 1A by concentration/ effect curves and clearly prove that AMS does not show any significant interference with the cell survival index, even at high in vitro concentrations $(>0.5 \mathrm{mg} / \mathrm{mL})$. As well, we even report a slight increase of cell viability in the presence of low micromolar concentrations of the extract. In line with this outcome, inversely correlated fluorescent measurements for the estimation of the live/dead cell ratio showed that AMS, for all the screened concentrations and times, does not interfere with HaCaT keratinocyte viability (Fig. 1B). In

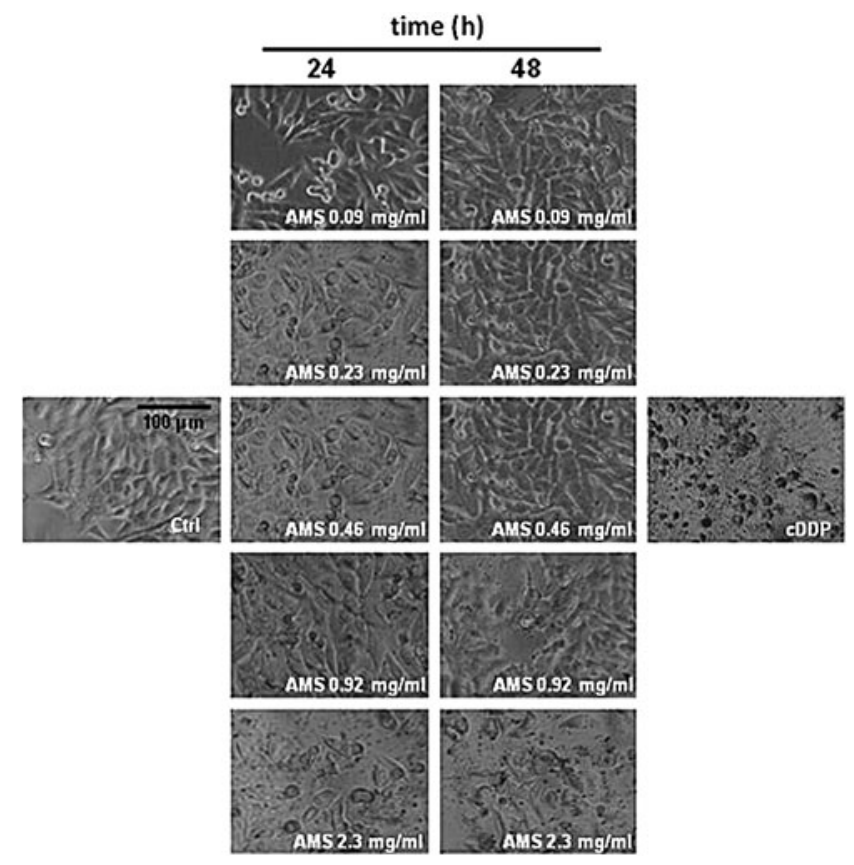

FIG. 2. AMS effects on cell monolayers. Representative microphotographs at a $200 \times$ magnification $(20 \times$ objective and a $10 \times$ eyepiece) by phase-contrast light microscopy of human keratinocytes treated for the indicated times $(24$ and $48 \mathrm{~h}$ ) with a range of concentrations (from 0.09 to $2.3 \mathrm{mg} / \mathrm{mL}$ ) of AMS (Annurca apple polyphenolic extract microencapsulated with maltodextrins, AppleMetS). The shown images are representative of three independent experiments. $\mathrm{IC}_{50}$ concentrations of cisplatin $(c \mathrm{DDP})$ are used as positive control for cytotoxicity. 
addition and to support, we monitored cellular morphology throughout the in vitro trials. Endpoint imaging by light microscopy was taken from cells to assess potential cellular monolayer modifications induced by incubation with different concentrations of the polyphenolic extract. The occurrence of changes in cell morphology as well as in monolayer appearance is generally suggestive of distinctive hallmarks of cell death pathway activation. Accordingly, with the cell survival index analysis, AMS proves to be very biocompatible, also at high final concentrations and after $48 \mathrm{~h}$ of incubation, so that no significant modifications of keratinocyte subconfluent monolayers were evidenced (Fig. 2). In conclusion, in vitro bioscreens suggest the theoretical safety of AMS administration to human keratinocytes under a wide range of experimental conditions, thus allowing to design further in vitro experiments on viable cells.

\section{In vitro AMS supplementation strongly enhances keratin content in human skin cells}

To explore AMS effect on the regulation of keratin expression, $\mathrm{HaCaT}$ cells were cultured in standard growth medium in the presence of tested concentrations of the extract $(0.23$ and $0.46 \mathrm{mg} / \mathrm{mL}$ ) for 24 and $48 \mathrm{~h}$, as determined by preliminary bioscreens. After incubations, the total cellular levels of keratins were evaluated by Western blot analysis using broad-spectrum anti-pan-keratin antibodies, as described in the Materials and
Methods section. Cytokeratin band identification was achieved by molecular-weight marker position. As clearly shown, in vitro treatments for $48 \mathrm{~h}$ resulted in a remarkable increase of keratin expression and this also occurs with a similar extent using a serum-free culture medium to exclude unspecific stimuli (Fig. 3). The cellular content of cytokeratins was clearly enhanced in all the examined conditions, reaching a notable maximum increase of about threefold with respect to untreated control cells following $48 \mathrm{~h}$ of exposure to extracts at $0.46 \mathrm{mg} /$ $\mathrm{mL}$. This effect was concentration and time dependent (Fig. 4), definitely due to the presence of AMS, as further suggested by the concurrent analysis of GAPDH protein, herein used as housekeeping gene. Noteworthy, the high-weight molecular cytokeratin isoforms - that is, $\mathrm{K} 1, \mathrm{~K} 4, \mathrm{~K} 5$ and $\mathrm{K} 6 / \mathrm{K} 10$ - visibly reached a very high expression level throughout treatments - an effect probably due to induction of protein synthesis coupled to protein accumulation. Accordingly, we can assume that, without affecting cell growth and proliferation, the AFA extract supplementation is able to induce a remarkable increase in keratin levels in human skin cells, under many experimental conditions and even at both relatively low concentrations $(<0.5 \mathrm{mg} / \mathrm{mL})$ and short exposure times $(24 \mathrm{~h})$.

\section{Enrollment and subject attrition}

Patients were enrolled in November 2015. A total of 340 patients were screened for eligibility; 90 patients $(26.5 \%)$

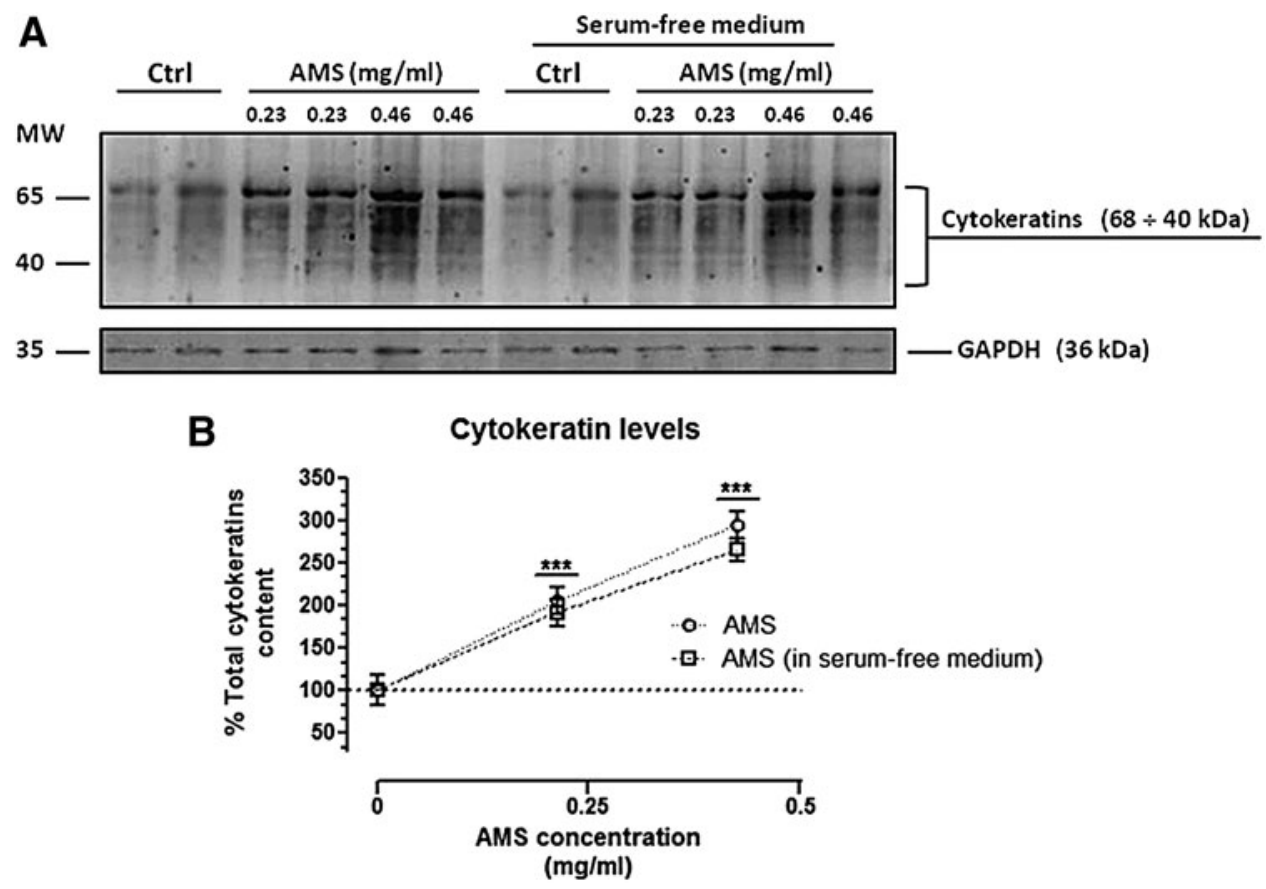

FIG. 3. Concentration-dependent effects of AMS on keratin expression in HaCaT cells. (A) Western blot analysis showing the keratin levels in $\mathrm{HaCaT}$ cells exposed to AMS (Annurca apple polyphenolic extract microencapsulated with maltodextrins, AppleMetS) (0.23 and $0.46 \mathrm{mg} / \mathrm{mL}$ ) for $48 \mathrm{~h}$, in the presence (left lanes) or absence of serum (right lanes), as indicated in figure. Equal amounts of proteins (70 $\mu \mathrm{g}) \mathrm{were}$ separated on a $10 \%$ SDS-polyacrylamide gel and subjected to Western blot analysis using monoclonal anti-pan-cytokeratin antibodies that recognize human cytokeratins ranging from 68 to $40 \mathrm{kDa}$, as reported in the Materials and Methods section. Shown are blots representative of three independent experiments. (B) After chemiluminescence, the keratin bands within each lane were quantified by densitometric analysis and plotted in line graph as percentage of control. The anti-GAPDH antibody was used to standardize the amounts of proteins in each lane. Shown are the averages \pm SEM values of three independent experiments. $* * * P<.001$ versus control (untreated cells). 
did not pass the screening stage and 250 patients were randomized. The most common reason was that patients did not meet the inclusion criteria at baseline $(n=38)$, followed by general refusal to participate for no specific reasons $(n=14)$, and concerns about the protocol, especially fear of placebo $(n=4)$. Some fulfilled exclusion criteria $(n=34)$.

Overall, 250 patients were assigned to the group assuming the two supplements: they were divided into two subgroups (each one comprising 125 patients), according to the two different supplements chosen for this study. Patients of both subgroups underwent a placebo period during the first 4 weeks before the treatment period of 8 weeks. Follow-up period lasted another 4 weeks. Figure 5 shows the flow of participants through the trials together with the completeness of diary information over the entire treatment period.

No patient prematurely terminated study participation before allocation to treatment. Figure 5 follows the $\mathrm{CON}$ SORT PRO reporting guideline ${ }^{34}$ and reveals that within the assessment period, the following percentage of patients for each subgroup provided data for the primary endpoint: subgroup AMS, 74.6\% (85 of 114 patients) and subgroup AMSbzs, $73.4 \%$ (83 of 113 patients). In each subgroup, a few patients did not submit any diaries, giving no specific reason for this. Completeness of the patient diaries did not differ between the treatment groups.

\section{Participants' baseline characteristics}

Table 1 shows the demographic and clinical characteristics assessed at the baseline visit of all 250 patients randomized. Interestingly, more than half of the randomized patients were female; the total age range was $30-83$ years. The groups were well balanced.

\section{Primary and secondary efficacy outcome measures}

No significant variation of hair number, weight, and keratin content with respect to the baseline values was registered at the end of placebo period in subjects belonging to both the supplement-supplied groups (Table 1). Analyzing results, we can assert that the administration of both supplements led to a statistically significant variation of all the clinical parameters. Specifically, AMSbzs supplement exerted the most important effects, increasing the hair number $/ \mathrm{cm}^{2}$ by $125.2 \%$ (95\% CI: $\left.-2.54, P=.0095\right)$, the hair
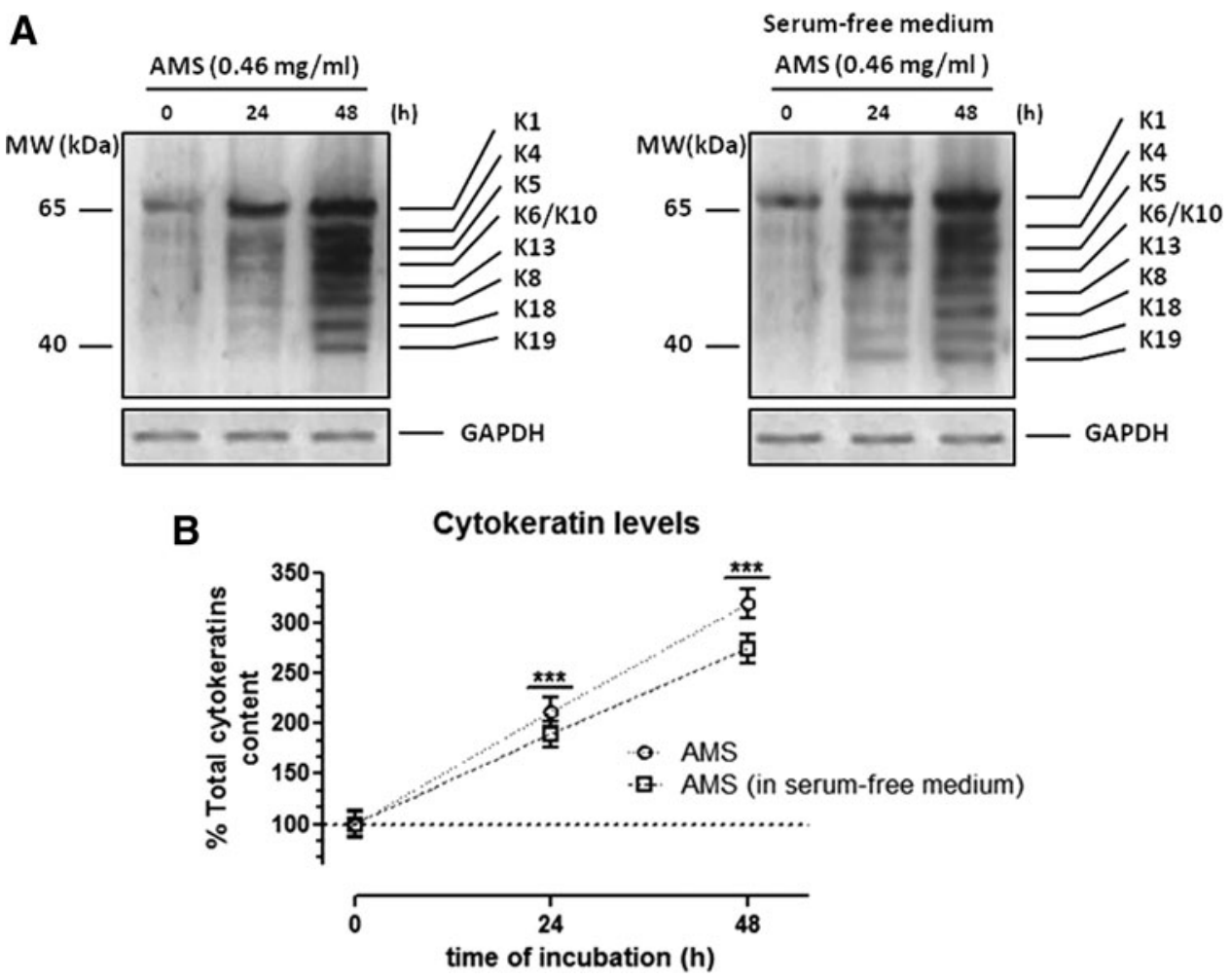

FIG. 4. Time course effects of AMS on keratin expression in HaCaT cells. (A) Western blot analysis for the evaluation of the keratin total content in HaCaT cells exposed for 24 and $48 \mathrm{~h}$ to $0.46 \mathrm{mg} / \mathrm{mL}$ of AMS (Annurca apple polyphenolic extract microencapsulated with maltodextrins, AppleMetS), in the presence (left blot) or absence (right blot) of serum. Equal amounts of proteins ( $70 \mu \mathrm{g}$ ) were separated on a $10 \%$ SDS-polyacrylamide gel and subjected to Western blot analysis using monoclonal anti-pan-cytokeratin antibodies that recognize the following human cytokeratins according to their molecular weight: K1 (68 kDa), K4 (59 kDa), K5 (58 kDa), K6/K10 (56 kDa), K13 (54 kDa), K8 (52 kDa), $\mathrm{K} 18(45 \mathrm{kDa})$, and K19 $(40 \mathrm{kDa})$. Shown are blots representative of three independent experiments. (B) The cytokeratin bands within each lane were quantified by densitometric analysis and plotted in line graph as percentage of control. The anti-GAPDH antibody was used to standardize the amounts of proteins in each lane. Shown are the averages \pm SEM values of three independent experiments. $* * * P<.001$ versus control (untreated cells). 


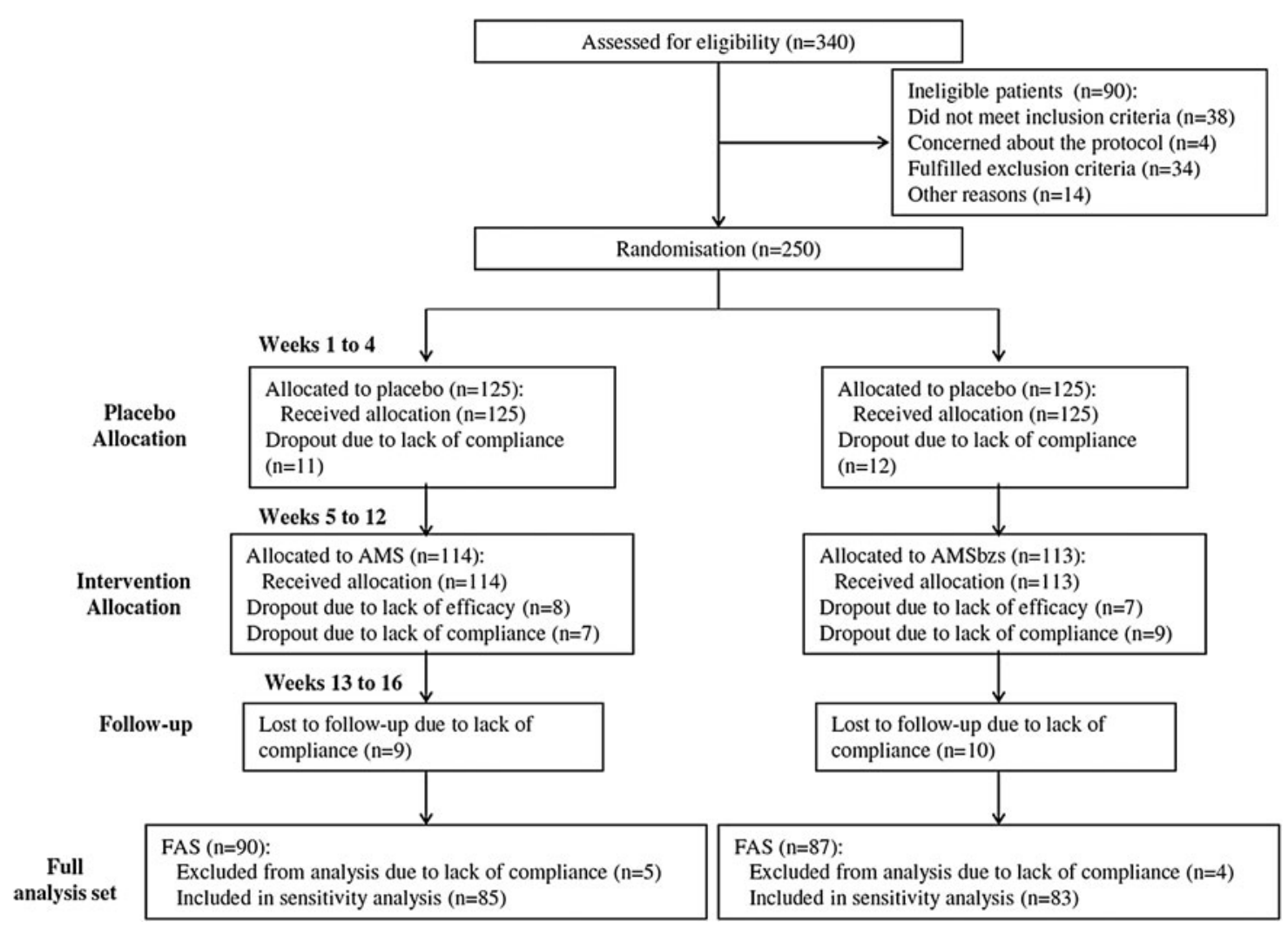

FIG. 5. Study flowchart according to the consolidated standards of reporting trials (CONSORT). The diagram shows enrollment and primary efficacy endpoints based on patient diaries, from prescreening to data collection; and the extent of exclusions, loss to follow-up, and completeness of diary documentation available across the entire trial period. AMS, Annurca apple polyphenolic extract microencapsulated with maltodextrins (AppleMetS); AMSbzs, formulation including Annurca apple polyphenolic extract microencapsulated with maltodextrins, biotin, selenium, and zinc (AppleMetS Hair); FAS, full analysis set.

weight by $42.1 \%$ (95\% CI: $-3.41, P=.0019)$, and the keratin content by $40.1 \%(95 \% \mathrm{CI}:-1.22, P=.0042)$, at the end of the trial period (Table 2) (Fig. 6). Noteworthy, very significant results were achieved already after 1 month of intervention study.

\section{Safety issues}

All the laboratory analyses concerning the hepatic and renal function indicated no alteration of values after 2 months of AMS treatment (Table 3). Other safety assessments, such as vital signs, blood pressure, or electrocardiographic findings, were all periodically monitored and baseline values did not change substantially during and at the end of the trial.

\section{Study strengths and limitations}

The major strengths of the clinical trial herein presented reside in the originality of the study and in the evaluation of the treatment effects in real-world settings. The positive results, herein reported, can inform physicians about a novel treatment/intervention, which can represent a valuable alternative in clinical practice. It has also been reported that the anagen ratio undergoes seasonal changes: it rises to a maximum in March and falls to a minimum in September. ${ }^{35}$ Our clinical test was performed from January to July, so the effects of seasonal changes are unlikely to have influenced the overall results. Conversely, the main limitations of our study include the short-term assessment for the treatment of a chronic condition and the choice of exclusively white race.

\section{DISCUSSION}

Polyphenols have always been essential antioxidants of the human diet. ${ }^{36-38}$ Among them, oligomeric procyanidins have also shown remarkable hair growth stimulant effects in vitro and in vivo, being able to promote hair epithelial cell growth and anagen induction of the hair cycle. ${ }^{14}$ In particular, procyanidins B2 and B3 show evidence of protective actions versus apoptosis in hair epithelial cell cultures, thereby restricting catagen induction in the hair cycle. ${ }^{39}$ Analyzing results (Table 2), we found that, on average, after 2 months, hair growth, weight, and keratin content increased by $118.3 \%, 37.3 \%$, and $35.7 \%$, respectively. Surprisingly, the coformulation named as AppleMetS Hair (AMSbzs), obtained by adding to the AMS supplement the vitamin biotin, and the minerals zinc and selenium, three elements well known for their positive general effects on hair and skin (Reg. EU No. 1924/2006), led the second subgroup of 
Table 1. Baseline Characteristics of Intention to Treat Sample According to Study Treatment

\begin{tabular}{|c|c|c|}
\hline Characteristics & $A M S(\mathrm{n}=125)$ & $\operatorname{AMSbzs}(\mathrm{n}=125)$ \\
\hline \multicolumn{3}{|l|}{ Placebo } \\
\hline \multicolumn{3}{|l|}{ Demographics } \\
\hline Age (years) & $42.4 \pm 10.6$ & $41.8 \pm 10.8$ \\
\hline Male, $n(\%)$ & $58(46.4)$ & $58(46.4)$ \\
\hline White ethnicity, $n(\%)$ & $125(100)$ & $125(100)$ \\
\hline \multicolumn{3}{|l|}{ Clinical parameters } \\
\hline Hair number $/ \mathrm{cm}^{2}$ & $16.4 \pm 4.6$ & $15.7 \pm 4.8$ \\
\hline Hair weight $(\mathrm{mg})^{\mathrm{a}}$ & $30.1 \pm 8.1$ & $29.6 \pm 7.9$ \\
\hline Keratin content $(\mathrm{mg})^{\mathrm{b}}$ & $27.4 \pm 6.4$ & $26.9 \pm 5.9$ \\
\hline Characteristics & $A M S(\mathrm{n}=114)$ & $\operatorname{AMSbzs}(\mathrm{n}=113)$ \\
\hline \multicolumn{3}{|l|}{ Treatment } \\
\hline \multicolumn{3}{|l|}{ Demographics } \\
\hline Age (years) & $43.5 \pm 10.2$ & $42.1 \pm 11.1$ \\
\hline Male, $n(\%)$ & $51(44.7)$ & $50(44.2)$ \\
\hline White ethnicity, $n(\%)$ & $114(100)$ & $113(100)$ \\
\hline Hair number $/ \mathrm{cm}^{2}$ & $15.9 \pm 4.8$ & $15.3 \pm 4.5$ \\
\hline Hair weight $(\mathrm{mg})^{\mathrm{a}}$ & $29.9 \pm 7.8$ & $30.1 \pm 8.0$ \\
\hline Keratin content $(\mathrm{mg})^{\mathrm{b}}$ & $27.2 \pm 5.5$ & $27.4 \pm 6.1$ \\
\hline
\end{tabular}

Values are mean $\pm \mathrm{SD}$.

AMS, Annurca apple polyphenolic extract microencapsulated with maltodextrins (AppleMetS); AMSbzs, formulation including Annurca apple polyphenolic extract microencapsulated with maltodextrins, biotin, selenium, and zinc (AppleMetS Hair).

${ }^{a}$ The weight is referred to an aliquot of 100 hairs $(1 \mathrm{~cm}$ long).

${ }^{\mathrm{b}}$ The keratin content is referred to an aliquot of 100 hairs ( $1 \mathrm{~cm}$ long).

$\mathrm{SD}$, standard deviation.

subjects to only slightly higher results in terms of hair growth, weight, and keratin content (Table 2), clearly indicating for AMS a major role in promoting hair growth and tropism. Despite the small number of subjects and the short period over which the trial was carried out, we observed a clear trend and significant results for both supplements in each subgroup, which were revealed by some statistical analyses toward increased hair growth and density (Table 2).

Some clinical trials have extensively demonstrated the positive hair-growing effects of procyanidin B2, a major dimeric procyanidin occurring in apples. ${ }^{14,16}$ Actually, these studies have exclusively investigated the potential benefits of topical applications of procyanidin B2 under the form of alcoholic solutions in mixture with other bioactive components. Kamimura and Takahashi have reported the effects of $1 \%$ procyanidin $\mathrm{B} 2$ tonic on human hair growth after sequential use for 6 months. ${ }^{14}$ A double-blind clinical test involving a total of 29 male subjects was performed. It was observed an increase of 6.7 total hairs $/ 0.25 \mathrm{~cm}^{2}$ after 6 months of procyanidin therapy. The same effects have been reported with minoxidil ${ }^{40-42}$ and finasteride (an inhibitor of type II $5 \alpha$-reductase, Merck) ${ }^{8}$ therapy for androgenetic alopecia. In $2 \%$ minoxidil treatment, an increase of 250 total hairs $/ 5.1 \mathrm{~cm}^{2}$ (calculated as 12.3 total hairs $/ 0.25 \mathrm{~cm}^{2}$ ) after 12-month therapy was reported. ${ }^{40}$ In finasteride treatment $(1 \mathrm{mg} /$ day, oral administration), an increase of 86 total hairs/ $5.1 \mathrm{~cm}^{2}$ (calculated as 4.22 total hairs $/ 0.25 \mathrm{~cm}^{2}$ ) after 12- month therapy was reported. ${ }^{8}$ The level of efficacy of $1 \%$ procyanidin B2 is concluded to compare favorably with minoxidil and finasteride therapy. ${ }^{15}$ As far as the procyanidins are concerned, it has been demonstrated that in murine epithelial cells, both procyanidins B2 and B3 are capable of increasing the anagen growth phase within hair cycle by means of their protective action on cellular apoptosis induced by the androgen-inducible cytokine transforming growth factor (TGF) $\beta 1$ and $\beta 2$, which normally cause a cell cycle block in favor of differentiation processes and are thereby supposed to trigger catagen induction in hair follicle. ${ }^{43}$ In the same way, procyanidins exhibited intensive biological effects in promoting hair epithelial cell growth in murine models in vivo, leading to increased hair density and terminal hair formation. ${ }^{39}$ Indeed, the addition of TGF- $\beta 1$ or TGF- $\beta 2$ to cultured murine hair epithelial cells dose dependently decreased cell growth by increasing apoptosis via the intrinsic caspase network, whereas the concurrent addition of procyanidin $\mathrm{B} 2$ to the culture medium counteracted both TGF- $\beta 1$ and TGF- $\beta 2$ effects, protecting cells from apoptotic pathway activation. Interestingly, Kamimura et al. also showed that procyanidin $\mathrm{B} 2$ upregulates the expression of MAPK/ERK kinase (MEK-1/2) in the hair epithelial cells, as well as their activation. ${ }^{39}$ MEK is a member of the MAPK signaling cascade that is generally activated by mitogens, so that when MEK is inhibited, cell proliferation is blocked and apoptosis is induced. ${ }^{44}$ Not surprisingly, components of the MAPK/ERK pathway mainly discovered in cancer cells, ${ }^{45}$ in which drugs able to reverse the "on" or "off" switch, are currently being investigated as cancer chemotherapeutics. ${ }^{46,47}$ However, it is still unclear whether these two suggestions are correlated and especially if procyanidins are able to interact with distinct cell membrane receptors involved in MAPK/ERK signaling pathways and/ or to directly interfere with this cascade of intracellular proteins.

During hair growth and proliferation, several cytokeratins expressed by epithelial cells orchestrate the assembly of typical IFs, which contribute in common with keratinassociated proteins (KAPs) in the production of the hair shaft within the keratinization process of the hair fiber. ${ }^{17}$ All the well-known 54 human keratins belonging to the IF proteins share common structural and functional features. In addition, evidently bundled as tonofilaments in epidermal tissue, keratin filaments are endowed with a key functional role in the integrity and mechanical stability of both the single epithelial and hair cells and, via cell contacts, of the whole epithelial tissue. ${ }^{18}$ As well, the central function of epidermis-type keratins is demonstrated by knockout mouse models and also throughout different human hereditary keratin diseases affecting skin and hair. ${ }^{20}$ Therefore, since keratins are fundamental in epidermal and hair development and homeostasis, the regulation of keratin expression appears to be a central event for rapid proliferating epidermal cells, as well as in hair follicle growth and maturation. To date, despite the use of dietary nutraceuticals and functional food supplements being greatly increased, studies concerning their biological effects on hair loss have 
Table 2. Effects of Annurca Apple Supplements on Clinical Parameters

\begin{tabular}{|c|c|c|c|c|}
\hline & AMS & $\Delta(\%)$ & AMSbzs & $\Delta(\%)$ \\
\hline \multicolumn{5}{|c|}{ Hair number $/ \mathrm{cm}^{2}$} \\
\hline$t 0$ & $16.4 \pm 4.6$ & & $15.7 \pm 4.8$ & \\
\hline$t 30$ & $25.3 \pm 4.8$ & +54.3 & $25.1 \pm 4.4$ & +60.1 \\
\hline$t 60$ & $35.8 \pm 5.1$ & +118.3 & $35.3 \pm 5.7$ & +125.2 \\
\hline \multicolumn{5}{|c|}{ Hair weight $(\mathrm{mg})^{\mathrm{a}}$} \\
\hline$t 0$ & $30.1 \pm 8.1$ & & $29.6 \pm 7.9$ & \\
\hline$t 30$ & $36.1 \pm 7.6$ & +20.1 & $37.2 \pm 6.8$ & +25.7 \\
\hline$t 60$ & $41.3 \pm 8.5$ & +37.3 & $42.1 \pm 7.9$ & +42.1 \\
\hline \multicolumn{5}{|c|}{ Keratin content $(\mathrm{mg})^{\mathrm{b}}$} \\
\hline$t 0$ & $27.4 \pm 6.4$ & & $26.9 \pm 5.9$ & \\
\hline$t 30$ & $32.4 \pm 7.0$ & +18.4 & $33.2 \pm 7.1$ & +23.5 \\
\hline$t 60$ & $37.2 \pm 6.9$ & +35.7 & $37.7 \pm 6.7$ & +40.1 \\
\hline
\end{tabular}

Values are mean $\pm \mathrm{SD}(n=5)$. Subjects were administered with two AMS or AMSbzs capsules/day for 2 months. Results were significantly different at a level of $P=.001$.

AMS, Annurca apple polyphenolic extract microencapsulated with maltodextrins (AppleMetS); AMSbzs, formulation including Annurca apple polyphenolic extract microencapsulated with maltodextrins, biotin, selenium, and zinc (AppleMetS Hair)

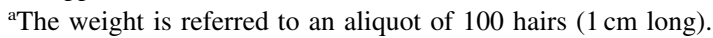

${ }^{\mathrm{b}}$ The keratin content is referred to an aliquot of 100 hairs $(1 \mathrm{~cm}$ long).

produced conflicting results. ${ }^{22}$ Conversely, by targeted bioscreens we have herein demonstrated that AMS supplementation in vitro is able to promote a remarkable upregulation of keratin expression in human keratinocytes, resulting in keratin accumulation within cells. These data are fully consistent with those arising from our clinical trial-indicating an important increase of the keratin hair content, of about $35 \%$ more than in the untreated group- thereby validating the biological effects of AMS on hair growing and proliferation. To the best of our knowledge, no correlation between the administration of nutraceuticals and actual increased expression of keratin in human skin cells had been reported so far. As well, this is the first study demonstrating the effectiveness of a natural procyanidin B2containing gastro-protected apple extract as hair growth stimulant via oral administration. For these reasons, we believe that the reported findings concerning the use of AMS as oral nutraceutical supplement are of great interest, as they reveal an efficacy in promoting hair growth fully comparable with or even higher than those obtained from trials performed with pharmaceutical therapies nowadays regarded as leading treatments for pattern baldness. In addition, our proposed therapy, apart from not giving any sign of hirsutism in all of the enrolled subjects, would allow avoiding the possible inconvenience deriving from topical application of a generic alcoholic solution (skin burning, reddening, and cracking), or, more importantly, specific side effects, which are typical of finasteride, such as sexual dysfunctions, ${ }^{48}$ or of minoxidil, such as cardiovascular, ${ }^{49-51}$ immunologic, ${ }^{52,53}$ and endocrine disorders. ${ }^{54}$ In fact, no evidences of cytotoxic effect nor morphological changes on cultured human keratinocytes were hitherto observed after exposure to AMS under different experimental conditions. Similarly, with the exception of antiproliferative effects on cancer cells and antibacterial activities, any type of cytotoxicity induced by apple bioactive components has never been reported in scientific literature. ${ }^{55-58}$

In conclusion, male and female pattern baldness is a highly common condition affecting $\sim 50 \%$ of the adult population, and potentially causing a significant negative impact on the quality of life. The results of this clinical trial, in combination with in vitro evidence of increased cellular

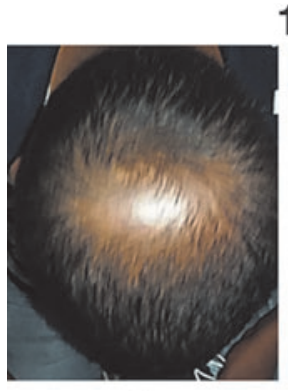

a

\section{3}

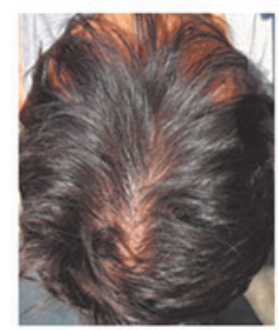

a
1

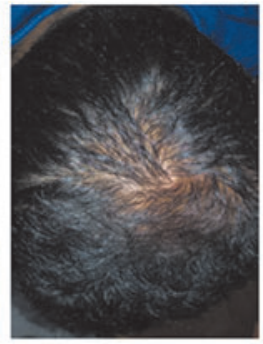

b

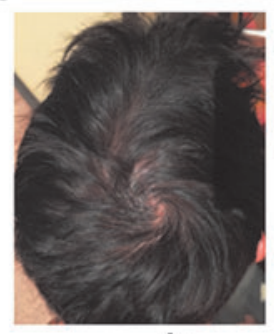

b

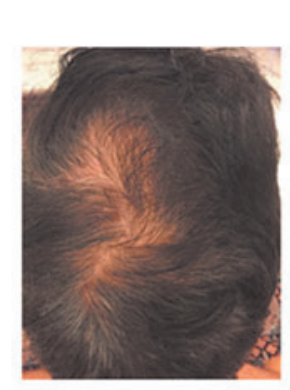

a

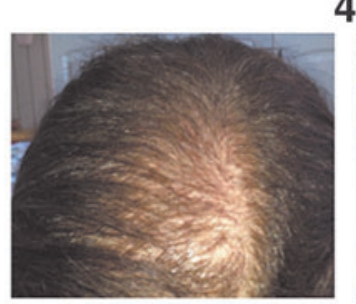

a

2

4

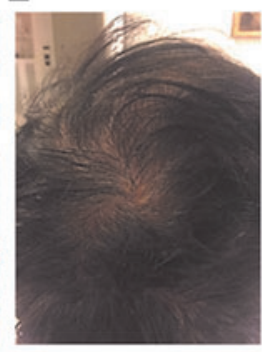

b

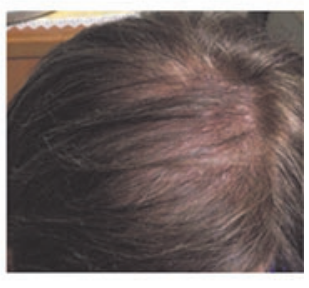

b
FIG. 6. Some examples of subjects $(1,2,3$ : males; 4 : female) who have consumed two capsules/day of AMSbzs supplement for 60 days (a: T0; b: T60). 
Table 3. Effects of Annurca Apple Supplements on Plasma Indicators of Hepatic and Renal Function in Subgroups

\begin{tabular}{|c|c|c|c|c|c|c|c|c|c|c|c|c|}
\hline \multicolumn{13}{|l|}{$A M S$} \\
\hline & \multicolumn{3}{|c|}{$A S T(G O T)(U / L)$} & \multicolumn{3}{|c|}{$A L T(G P T)(U / L)$} & \multicolumn{3}{|c|}{$\gamma-G T P(U / L)$} & \multicolumn{3}{|c|}{$A L P(U / L)$} \\
\hline & t 0 & t 30 & t 60 & t 0 & t 30 & t 60 & t 0 & t 30 & t 60 & t 0 & t 30 & t 60 \\
\hline \multirow{4}{*}{$\begin{array}{l}\text { Mean value } \\
\Delta(\%)\end{array}$} & 21.6 & 21.5 & 21.5 & 27.9 & 27.5 & 27.6 & 37.2 & 36.2 & 34.4 & 222.6 & 220.4 & 215.9 \\
\hline & & -0.5 & -0.5 & & -1.4 & -1.1 & & -2.7 & -7.5 & & -0.98 & -3.0 \\
\hline & \multicolumn{3}{|c|}{$L D H(U / L)$} & \multicolumn{3}{|c|}{ Albumin $(g / d L)$} & \multicolumn{3}{|c|}{ Total bilirubin $(\mathrm{mg} / \mathrm{dL})$} & \multicolumn{3}{|c|}{ Creatinine $(m g / d L)$} \\
\hline & t 0 & t 30 & t 60 & t 0 & t 30 & t 60 & t 0 & t 30 & t 60 & t 0 & t 30 & t 60 \\
\hline $\begin{array}{l}\text { Mean value } \\
\Delta(\%)\end{array}$ & 177.0 & $\begin{array}{c}176.5 \\
-0.28\end{array}$ & $\begin{array}{c}170.2 \\
-3.84\end{array}$ & 4.31 & $\begin{array}{r}4.32 \\
+0.23\end{array}$ & $\begin{array}{r}4.16 \\
-3.48\end{array}$ & 0.57 & $\begin{array}{c}0.57 \\
-\end{array}$ & $\begin{array}{r}0.54 \\
-5.26\end{array}$ & 0.84 & $\begin{array}{r}0.82 \\
-2.38\end{array}$ & $\begin{array}{c}0.80 \\
-4,76\end{array}$ \\
\hline
\end{tabular}

AMSbzs

\begin{tabular}{|c|c|c|c|c|c|c|c|c|c|c|c|c|}
\hline & \multicolumn{3}{|c|}{$A S T(G O T)(U / L)$} & \multicolumn{3}{|c|}{$A L T(G P T)(U / L)$} & \multicolumn{3}{|c|}{$\gamma-G T P(U / L)$} & \multicolumn{3}{|c|}{$A L P(U / L)$} \\
\hline & t 0 & t 30 & t 60 & t 0 & t 30 & t 60 & t $O$ & t 30 & t 60 & t 0 & t 30 & t 60 \\
\hline \multirow{4}{*}{$\begin{array}{l}\text { Mean value } \\
\Delta(\%)\end{array}$} & 21.8 & 21.8 & 21.7 & 27.3 & 26.9 & 27.0 & 37.4 & 35.7 & 34.8 & 222.8 & 220.6 & 214.7 \\
\hline & & - & -0.46 & & -1.46 & -1.10 & & -4.54 & -6.95 & & -0.99 & -3.63 \\
\hline & \multicolumn{3}{|c|}{$L D H(U / L)$} & \multicolumn{3}{|c|}{ Albumin $(g / d L)$} & \multicolumn{3}{|c|}{ Total bilirubin $(\mathrm{mg} / \mathrm{dL})$} & \multicolumn{3}{|c|}{ Creatinine $(m g / d L)$} \\
\hline & t 0 & t 30 & t 60 & t $O$ & t 30 & t 60 & $\mathrm{t} O$ & t 30 & t 60 & t 0 & t 30 & t 60 \\
\hline $\begin{array}{l}\text { Mean value } \\
\Delta(\%)\end{array}$ & 179.9 & $\begin{array}{c}178.8 \\
-0.28\end{array}$ & $\begin{array}{c}172.2 \\
-3.84\end{array}$ & 4.41 & $\begin{array}{r}4.32 \\
+0.23\end{array}$ & $\begin{array}{r}4.23 \\
-3.48\end{array}$ & 0.59 & $\begin{array}{c}0.57 \\
-\end{array}$ & $\begin{array}{r}0.54 \\
-5.26\end{array}$ & 0.83 & $\begin{array}{r}0.80 \\
-2.38\end{array}$ & $\begin{array}{c}0.79 \\
-4,76\end{array}$ \\
\hline
\end{tabular}

Values are mean $\pm \mathrm{SD}(n=5)$. Subjects were administered with two AMS or AMSbzs capsules/day for 2 months. Results were significantly different at a level of $P=.001$. AMS, Annurca apple polyphenolic extract microencapsulated with maltodextrins (AppleMetS); AMSbzs, formulation including Annurca apple polyphenolic extract microencapsulated with maltodextrins, biotin, selenium, and zinc (AppleMetS Hair); AST, aspartate aminotransferase; GOT, glutamic oxaloacetic transaminase; ALT, alanine transaminase; GPT, glutamic pyruvic transaminase; $\gamma$-GTP, gamma-glutamyl transpeptidase; ALP, alkaline phosphatase; LDH, lactate dehydrogenase.

keratin content, provide strong support that a dietary supplement acting as a nutraceutical and based on a procyanidin B2-containing AFA natural extract can effectively promote hair growth and improve skin quality, at once increasing hair density, weight, and keratin content. Further studies are ongoing to better clarify the molecular basis of the procyanidin-induced growth promotional effects at the skin level, focusing on both the regulation of cell homeostasis and the functional role played by keratins selectively induced via nutraceutical supplementation.

\section{AUTHORS' CONTRIBUTIONS}

All authors have contributed significantly and all authors are in agreement with the content of the article. All authors were responsible for study concept and design. G.C.T., D.C., G.B., M.D.A., and E.N. acquired the clinical data. R.S., C.I., and M.P. acquired the in vitro data. All authors analyzed and interpreted the data and drafted the article. All authors critically revised the article for important intellectual content. E.N. obtained funding. E.N. provided administrative, technical, or material support. All authors supervised the study. All authors, external and internal, had full access to all of the data. E.N. is the guarantor.

\section{ACKNOWLEDGMENT}

This research was funded by Regione Campania under POR Campania FESR 2007-2013-O.O. 2.1 (FarmaBioNet).

\section{AUTHOR DISCLOSURE STATEMENT}

No competing financial interests exist.

\section{REFERENCES}

1. Kelly Y, Blanco A, Tosti A: Androgenetic alopecia: An update of treatment options. Drugs 2016;76:1349-1364.

2. Hoffmann R: Hormonal interaction and hair growth. Ann Dermatol Venereol 2002;129:787-792.

3. Buhl AE, Conrad SJ, Waldon DJ, Brunden MN: Potassium channel conductance as a control mechanism in hair follicles. $J$ Invest Dermatol 1993;101:148S-152S.

4. Kulick MI: Topical minoxidil: Its use in treatment of male pattern baldness. Ann Plast Surg 1988;21:273-275.

5. Olsen EA: Treatment of androgenetic alopecia with topical minoxidil. Resid Staff Physician 1989;35:53-69.

6. Dallob AL, Sadick NS, Unger W, et al.: The effect of finasteride, a 5 alpha-reductase inhibitor, on scalp skin testosterone and dihydrotestosterone concentrations in patients with male pattern baldness. J Clin Endocrinol Metab 1994;79:703-706.

7. Gormley GJ: Finasteride: A clinical review. Biomed Pharmacother 1995;49:319-324. 
8. Kaufman KD, Olsen EA, Whiting D, et al:: The Finasteride Male Pattern Hair Loss Study Group: Finasteride in the treatment of men with androgenetic alopecia. J Am Acad Dermatol 1998;39: 578-589.

9. Wilson C, Walkden V, Powell S, et al.: Contact dermatitis in reaction to $2 \%$ topical minoxidil solution. J Am Acad Dermatol 1991;24:661-662.

10. Boeck C, Parker J, Shank J, Hordinsky M: Safety of long term therapy with $3 \%$ and $5 \%$ topical minoxidil in female androgenetic alopecia. In: Hair Research for the Next Millenium. Elsevier, Amsterdam, 1996, pp. 61-65.

11. Nickel JC, Fradet Y, Boake RC, et al.: Efficacy and safety of finasteride therapy for benign prostatic hyperplasia: Results of a 2-year randomized controlled trial (the PROSPECT study). PROscar Safety Plus Efficacy Canadian Two year Study. CMAJ 1996;155:1251-1259.

12. Wilton L, Pearce G, Edet E, Freemantle S, Stephens MD, Mann RD: The safety of finasteride used in benign prostatic hypertrophy: A non-interventional observational cohort study in 14,772 patients. Br J Urol 1996;78:379-384.

13. Takahashi T, Kamiya T, Hasegawa A, Yokoo Y: Procyanin oligomers selectively and intensively promote proliferation of mouse hair epithelial cells in vitro and activate hair follicle growth in vivo. J Invest Dermatol 1999;112:310-316.

14. Kamimura A, Takahashi T: Procyanidin B-2, extracted from apples, promotes hair growth: A laboratory study. Br J Dermatol 2002;146:41-51.

15. Kamimura A, Takahashi T, Waranabe Y: Investigation of topical application of procyanidin B-2 from apple to identify its potential use as a hair growing agent. Phytomedicine 2000;7:529-536.

16. Takahashi T, Kamimura A, Yokoo Y, Honda S, Watanabe Y: The first clinical trial of topical application of procyanidin B-2 to investigate its potential as a hair growing agent. Phytother Res 2001;15:331-336.

17. Makar IA, Havryliak VV, Sedilo HM: Genetic and biochemical aspects of keratin synthesis by hair follicles. Tsitol Genet 2007; 41:75-79.

18. Schweizer J, Bowden PE, Coulombe PA, et al: New consensus nomenclature for mammalian keratins. J Cell Biol 2006;174: 169-174.

19. Gu LH, Coulombe PA: Keratin function in skin epithelia: A broadening palette with surprising shades. Curr Opin Cell Biol 2007;19:13-23.

20. Moll R, Divo M, Langbein L: The human keratins: Biology and pathology. Histochem Cell Biol 2008;129:705-733.

21. Tenore GC, Campiglia P, Stiuso P, Ritieni A, Novellino E: Nutraceutical potential of polyphenolic fractions from Annurca apple (M. pumila Miller cv Annurca). Food Chem 2013;140:614622.

22. Miniaci MC, Irace C, Capuozzo A, et al: : Cysteine prevents the reduction in keratin synthesis induced by iron deficiency in human keratinocytes. J Cell Biochem 2016;117:402-412.

23. Breitkreutz D, Schoop VM, Mirancea N, Baur M, Stark HJ, Fusenig NE: Epidermal differentiation and basement membrane formation by $\mathrm{HaCaT}$ cells in surface transplants. Eur J Cell Biol 1998;75:273-286.

24. Tenore GC, Campiglia P, Ritieni A, Novellino E: In vitro bioaccessibility, bioavailability and plasma protein interaction of polyphenols from Annurca apple (M. pumila Miller cv Annurca). Food Chem 2013;141:3519-3524.
25. Lo Scalzo R, Testoni A, Genna A: "Annurca" apple fruit, a southern Italy apple cultivar: Textural properties and aroma composition. Food Chem 2001;73:333-343.

26. Vitiello G, Luchini A, D'Errico G, et al.: Cationic liposomes as efficient nanocarriers for the drug delivery of an anticancer cholesterolbased ruthenium complex. J Mater Chem B 2015;3:3011-3023.

27. Achtstaetter T, Hatzfeld M, Quinlan RA, Parmelee DC, Franke WW: Separation of cytokeratin polypeptides by gel electrophoretic and chromatographic techniques and their identification by immunoblotting. Methods Enzymol 1986;134:355-371.

28. Prosky L, Asp NG, Schweizer TF, DeVries JW, Furda I: Determination of insoluble, soluble, and total dietary fibre in foods and food products. Interlaboratory study. J Assoc Off Anal Chem 1988;71:1017-1023.

29. Little RJ, Rubin DB: Statistical Analysis with Missing Data. John Wiley \& Sons, Hoboken, NJ, 2002.

30. Molenberghs G, Thijs H, Jansen I, et al:: Analyzing incomplete longitudinal clinical trial data. Biostatistics 2004;5:445-464.

31. O'Kelly M, Ratitch B: Clinical trials with missing data: A guide for practitioners. John Wiley \& Sons, Hoboken, NJ, 2014.

32. White IR, Carpenter J, Horton NJ: Including all individuals is not enough: Lessons for intention-to-treat analysis. Clin Trials 2012; 9:396-407.

33. Carpenter JR, Kenward MG: Missing data in randomised controlled trials-A practical guide. National Institute for Health Research 2007. Publication RM03/JH17/MK, http://missingdata. 1shtm.ac.uk/downloads/rm04_jh17_mk.pdf (accessed November 10, 2016).

34. Calvert M, Blazeby J, Altman DG, Revicki DA, Moher D, Brundage MD: CONSORT PRO Group. Reporting of patientreported outcomes in randomized trials: The CONSORT PRO extension. JAMA 2013;309:814-822.

35. Randall VA, Ebling EJG: Seasonal changes in human hair growth. Br J Dermtol 1991;124:146-151.

36. Ferreira D, Slade D: Oligomeric proanthocyanidins: Naturally occurring O-heterocycles. Nat Prod Rep 2002;19:517-541.

37. Cos P, De Bruyne T, Hermans N, Apers S, Berghe DV, Vlietinck AJ: Proanthocyanidins in healthcare: Current and new trends. Curr Med Chem 2004;11:1345-1359.

38. Fu C, Yang D, Peh WY, Lai S, Feng X, Yang H: Structure and antioxidant activities of proanthocyanidins from elephant apple (Dillenia indica Linn.). J Food Sci 2015;80:2191-2199.

39. Kamimura A, Takahashi T, Morohashi M, Takano Y: Procyanidin oligomers counteract TGF-beta1- and TGF-beta2-induced apoptosis in hair epithelial cells: An insight into their mechanisms. Skin Pharmacol Physiol 2006;19:259-265.

40. Kreindler TG: Topical minoxidil in early androgenetic alopecia. J Am Acad Dermatol 1987;16:718-724.

41. Roberts JL: Androgenetic alopecia: Treatment results with topical minoxidil. J Am Acad Dermatol 1987;16:705-710.

42. Savin RC: Use of topical minoxidil in the treatment of male pattern baldness. J Am Acad Dermatol 1987;16:696-704.

43. Hibino T, Nishiyama T: Role of TGF-beta2 in the human hair cycle. J Dermatol Sci 2004;35:9-18.

44. Wellbrock C, Arozarena I: The complexity of the ERK/MAPkinase pathway and the treatment of melanoma skin cancer. Front Cell Dev Biol 2016;4:33.

45. Santarpia L, Lippman SM, El-Naggar AK: Targeting the MAPKRAS-RAF signaling pathway in cancer therapy. Expert Opin Ther Targets 2012;16:103-119. 
46. Asati V, Mahapatra DK, Bharti SK: PI3K/Akt/mTOR and Ras/ Raf/MEK/ERK signaling pathways inhibitors as anticancer agents: Structural and pharmacological perspectives. Eur J Med Chem 2016;109:314-341.

47. Rusconi P, Caiola E, Broggini M: RAS/RAF/MEK inhibitors in oncology. Curr Med Chem 2012;19:1164-1176.

48. Mysore V: Finasteride and sexual side effects. Indian Dermatol Online J 2012;3:62-65.

49. Pettinger WA: Minoxidil and the treatment of severe hypertension. N Engl J Med 1980;303:922-926.

50. Reichgott MJ: Minoxidil and pericardial effusion: An idiosyncratic reaction. Clin Pharmacol Ther 1981;30:64-70.

51. Krehlik JM, Hindson DA, Crowley JJ, Knight LL: Minoxidilassociated pericarditis and fatal cardiac tamponade. West $J$ Med 1985;143:527-529.

52. Tunkel AR, Shuman M, Popkin M, Seth R, Hoffman B: Minoxidilinduced systemic lupus erythematosus. Arch Intern Med 1987;147: 599-600.
53. Mitas JA: Development of antinuclear antibodies during minoxidil therapy. Arthritis Rheum 1981;24:570-571.

54. Nguyen KH, Marks JG: Pseudoacromegaly induced by the longterm use of minoxidil. J Am Acad Dermatol 2009;48:962-965.

55. Luo J, Zhang P, Li S, Shah NP: Antioxidant, antibacterial, and antiproliferative activities of free and bound phenolics from peel and flesh of Fuji apple. J Food Sci 2016;81:1735-1742.

56. Schiavano GF, De Santi M, Brandi G, et al.: Inhibition of breast cancer cell proliferation and in vitro tumorigenesis by a new red apple cultivar. PLoS One 2015;10:e0135840.

57. Sudan S, Rupasinghe HP: Flavonoid-enriched apple fraction AF4 induces cell cycle arrest, DNA topoisomerase II inhibition, and apoptosis in human liver cancer HepG2 cells. Nutr Cancer 2014; 66:1237-1246.

58. Hyson D, Studebaker-Hallman D, Davis PA, Gershwin ME: Apple juice consumption reduces plasma low-density lipoprotein oxidation in healthy men and women. J Med Food 2009;3: 159-166. 